\title{
Human Indoor Exposome of Chemicals in Dust and Risk Prioritization
}

5 Ting Dong ${ }^{1,2 \#}$, Yingdan Zhang ${ }^{2, \#}$, Shenglan $\mathrm{Jia}^{3}$, Hongtao Shang ${ }^{3}$, Wenjuan $\mathrm{Fang}^{3}$, Da Chen ${ }^{1}$,

$6 \quad$ Mingliang Fang $2,3 *$

$7 \quad$ *Corresponding authors: dachen@,jnu.edu.cn and mlfang@,ntu.edu.sg

8

9 Contents

10 Text S1, Chemical search.

Page

$11 \mathrm{~S} 2$

12 Text S2, Human dust exposure calculations.

Page

$13 \quad \mathrm{~S} 3$

14 Text S3, In vitro and in vivo toxicity search.

Page

15 S5

16 Text S4, Methods for figure generation.

Page

17 S6

18 Text S5, In vitro and in vivo, epidemiological toxicity of dust extract and causal chemical 19 identification.

Page

$20 \quad$ S7

21 Table S1. Non-Dietary ingestion and dermal dose equation.

Page

$22 \quad \mathrm{~S} 11$

23 Table S2. Exposure Factor Mean (CV) values for dose calculations ${ }^{\mathrm{a}}$.

Page

$24 \quad \mathrm{~S} 12$

25 Table S3. General model characteristics.

Page

$26 \quad \mathrm{~S} 13$ 
27 Table S4. Chemical abbreviation used in this study.

Page

$28 \quad \mathrm{~S} 14$

29 Figure S1. The variation of averaged median concentrations of indoor dust chemicals across

30 studies $(n \geqslant 4)$.

Page

31 S15

32 Figure S2. Chemical contributions in every assay.

Page S16

33

Figure S3. Toxicity contribution from chemicals in dust in two ER $\alpha$ agonist assays.

Page S17

34

35 Text S1, Chemical search.

36 Briefly, a search with "dust", "house dust" or "indoor dust" and "chemical" resulted in over

37 5,000 publications in National Center for Biotechnology Information database PubMed

38 (https://www.ncbi.nlm.nih.gov/pubmed/) and Web of Science (www.webofknowledge.com/).

39 The publication dates were further filtered from Year 2000 to 2019. All the abstracts were

40 downloaded as a database for future search. Meanwhile, we have prepared a targeted chemical 41 list summarized from previous databases such as ToxCast database

42 (https://actor.epa.gov/dashboard/), NIEHS database (http://www.niehs.nih.gov), Biomonitoring 43 California (https://biomonitoring.ca.gov/) and Human Blood Exposome

44 (https://www.cdc.gov/exposurereport/index.html). Studies that include less than 5 dust samples 45 were excluded from further analysis. The studies from special sampling areas, such as 46 occupational areas and accidental treatment zones, were also excluded. In addition, the chemicals 47 from untargeted analyses in dust samples were included [1, 2]. Besides the synthesized 48 compounds, some biogenic compounds, such as fatty acids and endotoxin, were also included in 49 the literature search.

50

51

52 
54 We calculated dose estimates $(\mu \mathrm{g} / \mathrm{kg} /$ day) for dust ingestion and dermal routes of exposure based on dust concentrations of pollutants reported:

$$
D_{\text {total }}=D_{\text {ing }}+D_{\text {derm_dust }}
$$

56 Where, $D_{\text {total }}$ is the total dose received ( $\mu \mathrm{g} / \mathrm{kg} /$ day), $D_{\text {ing }}$ is the non-dietary ingestion of dust dose,

$57 D_{\text {derm-dust }}$ is the dermal dose through dust adherence (Table S1) follow the equations presented

58 in the Agency for Toxic Substances \& Disease Registry's Public Health Assessment Guidance

59 Manual [3].

60

61 We assigned a lower bound of 8 hours per day and an upper bound of 12 hours per day for the 62 number of hours spent in residential houses. Based on this maxima and minima frequency of 63 exposure, we calculated an exposure factor (EF) to range the dose received only in residential 64 house. We assumed that adults spent 7 days per week and 52 weeks per year (which accounts for 65 four weeks away from residential houses for holidays and vacation). The EF is calculated:

$$
E F=\frac{\left(\frac{F}{24 \text { hours }}\right) \times 7\left(\frac{\text { days }}{\text { weeks }}\right) \times 52\left(\frac{\text { weeks }}{\text { year }}\right) \times 1(\text { year })}{1(\text { year }) \times 365\left(\frac{\text { days }}{\text { year }}\right)}
$$

66 Where, $\mathrm{F}$ is time of exposure per day (h).

67 Then estimated daily exposure was calculated as:

$$
\text { estimated daily exposure }=B W \times D_{\text {total }}
$$

69 Except for the exposure factor, input parameters were assumed to be normally or log-normally 70 distributed. The exposure factors handbook occasionally gives mean $(\mu)$ and $95 \%$ ile values for 71 exposure factors. In these cases, standard deviations $(\sigma)$ for normal distributions were calculated:

$$
\sigma=\frac{95 \operatorname{th}^{\text {ile }}-\mu}{1.96}
$$


72 To sample from the log-normal distribution, the logged mean $\left(\mu_{\log }\right)$ and logged $\operatorname{SD}\left(\sigma_{\log }\right)$ were 73 calculated:

$$
\begin{gathered}
\mu_{\log }=\ln (\mu)-\frac{1}{2} \ln \left(1+\frac{\sigma^{2}}{\mu^{2}}\right) \\
\sigma_{\log }=\sqrt{\ln \left(1+\frac{\sigma^{2}}{\mu^{2}}\right)}
\end{gathered}
$$

74 Therefore, lognormal parameters $(\theta)$ were randomly sampled using the distribution, $75 \log (\theta) \sim \mathrm{N}\left(\theta_{\log }, \sigma_{l o g}^{2}\right)$.

76 For most input parameters, coefficient of variations (CVs), which are normalized measure of 77 dispersion or variability, were as signed to account for the uncertainty and variability. CVs are the 78 ratio of the arithmetic standard deviation $(\sigma)$ to the arithmetic mean $(\mu)$ :

$$
C V=\frac{\sigma}{\mu}
$$

79 Following recommendations on $\mathrm{CV}$ interpretations presented in the CalTox manual, CV values $80 \quad 0.1$ and below are considered reliable and contributed little to variability in the model. CV values 81 between 0.1 and 0.3 indicate the parameter was measured or obtained from a highly reliable 82 estimation method. $\mathrm{CV}$ values within this range reflect typical measurement variability and 83 uncertainty in extrapolating from experimental to environmental conditions. CV values between 840.3 and 3 indicate a parameter with a somewhat reliable estimation method.

85 
89 The NCBI PubMed database was searched using the following keywords: "house dust" or 90 "indoor dust" and "endocrine disruption", "epidemiological toxicity", "disease" or "immunity". 91 Papers published in English and with available full text matching the eligible criteria were 92 retrieved. These papers were extensively summarized to understand the toxicological effect of 93 house dust exposure on endocrine disruption, disease occurrence or immune activity in vitro, in 94 vivo or in human.

95 


\section{Text S4, Methods for figure generation.}

97 Figure 1(A) and Figure 2(A and B) were generated by OriginLab (OriginLab Corporation, 98 2018b). Figure 4 were generated by GraphPad Prism 6. The heatmap figures (Figure 5) were 99 generated by $\mathrm{R}$ ( $\mathrm{R}$ Core Team, 3.5.1, heatmap.2). The other figures were generated and 100 processed by Microsoft PowerPoint and Excel.

101

102 
Text S5, In vitro and in vivo, epide miological toxicity of dust extract and causal chemical identification.

The health effects of indoor dust extract were thoroughly evaluated by searching NCBI PubMed database, and the toxicological effect of house dust exposure was summarized. The causal chemicals for these toxicities were also investigated if available.

\section{Endocrine dis ruption effects via nuclear receptors: $A h R, A R, E R \alpha, P P A R \gamma$}

The endocrine disruption effects of house dust chemicals were extensively studied by evaluating nuclear hormone-disrupting potency as markers of in vitro toxicity. AhR agonistic effect is the one with most hits in previous studies. For example, Suzuki et al. [4] conducted an effectdirected analysis using dioxin-responsive chemical-activated luciferase gene expression (DRCALUX) assay and gas chromatography-high-resolution mass spectrometry (GC-HRMS) to investigate the dioxin-like activities of 33 dust extracts, and found that polybrominated dibenzofurans (PBDFs) is responsible for in vitro AhR activity in Japanese indoor dust. In another study [5], a yeast-based reporter gene assay using the recombinant YCM3 strain showed significant AhR agonist, antiandrogenic, antithyroid hormonal, and genotoxic activities in dust samples. Particularly, indoor dust obtained from computer rooms and laboratories exhibited elevated AhR agonist activities (16112 and 9686 ng benzo(a)pyrene equivalent/g dust, respectively), which are similar to or greater than those detected in indoor dust from New York and Japan, but lower than those in street dust collected from Vietnam and India [6-8]. However, $\mathrm{AhR}$ agonistic PAHs are minor contributors to bioassay-derived AhR agonist activities. In addition, higher AR antagnoist activities were detected in indoor dust samples from offices and classrooms, respectively, indicating that contaminants varied in different indoor dust samples. Another comprehensive toxicity test of indoor dust extracts using human-cell-based CALUX reporter gene assays based on human osteosarcoma (U2OS) cell lines were performed to characterize the endocrine-disrupting potencies of indoor dusts collected from Japan ( $n=8)$, US $(n=21)$, Vietnam $(n=10)$, the Philippines $(n=17)$, and Indonesia $(n=10)$ and of 23 selected FRs [9]. The results clearly showed that indoor dust extracts were agonistic to ER $\alpha$, GR (glucocorticoid receptor) and PPAR 2 , and antagonistic against AR, PR (progesterone receptor), GR and PPAR $\gamma 2$. Hierarchical clustering indicated that the agonism of ER $\alpha$ and the antagonism of AR and PR are common. An association analysis between the activity and chemical composition of 
the dust extract showed that flame retardants might play an important role in the observed endocrine disruption. Kennedy et al. [10] reported that the ER-agonistic activity of indoor air was about 1000 times more potent than that of outdoor air; however, total AhR activity was the highest in outdoor air, suggesting that indoor air is a potential source of estrogenic activity.

As for PPAR $\gamma$, several common environmental contaminants have been confirmed to significantly bind with and activate PPAR $\gamma$ signaling, including tributyltin (TBT), triphenyltin (TPT), and MEHP (a metabolite of DEHP). It is also reported that MEHP exhibited much stronger PPAR $\gamma$ binding potency than its parent compound, DEHP [11, 12]. Fang et al. [13] observed that 21 of the 24 tested indoor dust samples showed significant PPAR $\gamma$ binding potency at a concentration of $3 \mathrm{mg}$ dust equivalent (DEQ)/mL. A follow-up study applied a reporter gene assay (GeneBLAzer PPAR $\gamma$ Assay, Invitrogen) to investigate the activation of PPAR $\gamma$ by SVOCs and chemical mixtures in house dust extracts [14]. A total of 28 out of 30 tested SVOCs or their metabolites were found to be weak or moderate PPAR $\gamma$ agonists. Significant PPAR $\gamma 1$ activation was also observed in 15 of 25 house dust extracts, suggesting possible PPAR 1 disruption by indoor dust expousre. Further studies were proceeded to identify the primary contributors driving the PPAR $\gamma 1$ activity in indoor dust by using an effect-directed analysis approach [15], and the results showed that fatty acids (FAs), including oleic acid and palmitic acid, were mainly responsible for the observed PPAR $\gamma$ activity.

\section{Adipogenic activity}

The global prevalence of obesity and metabolic disorders is currently of great societal concern. The environmental "obesogens" studies have revealed many indoor pollutants such as organotins, plasticizers and some flame retardants can disrupt normal development and balance of lipid metabolism, leading to obesity $[16,17]$. To follow up with the environmental "obesogens" concept, some studies have investigated the adipogenic activity of indoor dust extracts. Kassotis et al. [18] used 3 T3-L1 mouse preadipocyte cell line as an in vitro model to assess the adipogenic activity of indoor dust extracts and a wide range of SVOCs which are known to be common indoor contaminants. The result showed 10 out of 11 indoor dust extracts triggered significant triglyceride accumulation and/or cell proliferation at environmentally relevant exposure levels $(<20 \mu \mathrm{g}$ of dust/well), and 28 of 44 SVOCs also exhibited significant adipogenic activities. Specifically, pyraclostrobin (a fungicide), dibutyl phthalate (DBP, a commonly used plasticizer), 
163

164

165

166

167

168

169

170

171

172

173

174

175

176

177

178

179

180

181

182

183

184

185

186

187

188

189

190

191

tert-butyl-phenyl diphenyl phosphate (TBPDP, a flame retardant), and the isopropylated triaryl phosphates (ITPs, a flame retardant) displayed near maximal or supra-maximal triglyceride accumulation relative to the rosiglitazone control. The observed adipogenic activity of house dust extracts occurred at concentrations below exposure levels estimated by EPA, raising concerns on the impacts on human metabolic health, particularly among children. In another study, several parabens promoted adipogenesis in murine 3T3-L1 cells, and the adipogenic potency increased with increasing length of the linear alkyl chain [19].

\section{Mutagenicity from dust extract}

Mutagenicity from house dust extracts has been reported in several studies. In one study, all of 52 tested house dust extracts elicited a significant mutagenic response with the mean mutagenic potencies ranged from 2293 to 23593 revertants per gram using the Salmonella Mutagenicity Test [20]. The companion research by Maertens et al. [21] showed that PAH concentrations displayed a significant positive relationship with mutagenic potency, indicating that PAHs accounted for the mutagenic activity of the dust samples. In contrast, a more recent non-targeted study in dust found that brominated azo dye such as bromo-dinitroaniline (BNA) could produce mutagenic effects at environmentally relevant concentrations, highlighting their potential health risk [22].

\section{Immune response from dust extract}

Dust exposure and its role in immune response for children has been a great focus in several recent studies. One study was designed to compare two distinctive U.S. farming populations, the Amish of Indiana and the Hutterites of South Dakota, with remarkably similar genetic ancestries and lifestyles but distinct asthma prevalence [23]. Twenty house dust samples were collected from Amish and Hutterite homes, and the intranasal instillation of dust extracts using a classic ovalbumin mouse model revealed that the house dust from Amish but not Hutterite homes significantly inhibited ovalbumin-induced airway hyperreactivity and eosinophilia, and these protective effects were abolished in mice that were deficient in MyD88 and Trif, critical molecules in innate immune signaling pathway. The causal compounds were suspected to be lipopolysaccharide (LPS) endotoxin and the protection against allergy was found through A20 induction in lung epithelial cells [24]. In another study, house dust extract could induce asthma 
192

193

194

195

196

197

198

199

200

201

202

203

204

205

206

207

208

209

210

211

212

213

214

215

216

217

218

219

220

via epithelial Toll-like receptor 4 (TLR4) [25]. The suspected causal compounds in dust are allergens, such as mites.

The NF- $\mathrm{KB}$ pathway is critical to both innate and adaptive immune responses in a wide variety of cell types. An intranasal house dust extract exposure regimen time course in CC10-I $\mathrm{KB} \alpha_{\mathrm{SR}}$ transgenic mice was used to evaluate the potential role of epithelial NF- $\kappa B$ to house dust extract [26]. Following a single exposure to dust extract, mRNA expression of proinflammatory mediators was clearly increased in lung tissue of wild-type (WT) mice, whereas CC10- IKB $\alpha_{\mathrm{SR}}$ mice exhibited significant decreases. This study demonstrated the functional importance of NF$\kappa \mathrm{B}$ activation (both classical and alternative pathways) in house dust-induced inflammation, airway hyperresponsiveness and airway remodeling. Both classical and alternative NF- $\mathrm{BB}$ pathways were determined to be activated in lung epithelial cells in response to diverse proinflammatory stimuli [27]. Activation of airway epithelial NF- $\kappa B$ pathway was demonstrated to be sufficient for promoting allergic sensitization to an innocuous inhaled antigen [28].

\section{Correlation between chemical exposure from dust and diseased condition}

To date, very few epidemiological studies have investigated the correlation between chemical exposure from dust and diseased condition. In one study, correlation analysis found that flame retardant tris (1,3-dichloro-2-propyl) phosphate (TDCPP) was positively associated with prolactin, inversely associated with free $\mathrm{T}_{4}$ and free androgen index (FAI); while triphenyl phosphate (TPP) was positively associated with prolactin and inversely associated with sperm concentrations. These results indicated that organophosphate flame retardants in house dust may be associated with altered hormone levels and decreased semen quality in men [29].

Dramatically increased incidence of thyroid cancer, especially papillary thyroid cancer (PTC), and increased using of flame retardants, raised the hypothesis that higher exposure to FRs may associate with increased PTC risk [30]. Higher concentrations of some flame retardants, particularly decabromodiphenyl ether (BDE-209) and tris (2-chloroethyl) phosphate (TCEP), were associated with increased chance of PTC. TCEP was more strongly associated with larger, more aggressive tumors, conversely, BDE-209 contributed to the risk of smaller, less aggressive PTCs. These results indicated that exposure to FRs in house environment, particularly BDE-209 and TCEP, may be related to increased risk of PTC occurrence and severity. 
221 Table S1. Non-Dietary ingestion and dermal dose equation.

\begin{tabular}{|c|c|c|}
\hline Routes & Equation & Description \\
\hline $\begin{array}{l}\text { Non- } \\
\text { dietary } \\
\text { ingestion }\end{array}$ & $D_{\text {ing }}=\frac{C d u s t \times I G R \times E F}{B W}$ & $\begin{array}{c}C_{\mathrm{dust}}: \text { contaminant concentration }(\mathrm{ug} / \mathrm{g}) \\
I G R \text { : Ingestion rate of indoor settled dust } \\
(\mathrm{g} / \mathrm{day})\end{array}$ \\
\hline $\begin{array}{c}\text { Dermal- } \\
\text { dust } \\
\text { adherence }\end{array}$ & $D_{\text {derm-dust }}=C_{\text {dust }} \times S A B W \times A E \times A \times A B S \times E F$ & $\begin{array}{l}S A B W \text { : body surface area to body weight ratio } \\
\left(\mathrm{m}^{2} / \mathrm{kg}\right) \\
A E: \text { fraction of body surface area exposed } \\
\quad \text { (unitless) } \\
A \text { : total soil adhered }\left(\mathrm{g} / \mathrm{m}^{2}\right) \\
A B S^{\mathrm{a}}: \text { dermal adsorption fraction (unitless) }\end{array}$ \\
\hline
\end{tabular}

${ }^{a}$ ABS: use of default ABS values: The California South Coast Air Quality Management District's Multi-Pathway 223 Health Risk Assessment Input parameters Gu idance Document [31] recommended using default values of 10\% for 224 organic chemicals and $1 \%$ for inorganic chemicals when quantitative data are not available to estimate chemical225 specific dermal absorption fractions from soil. 
228 Table S2. Exposure Factor Mean (CV) values for dose calculations ${ }^{\mathbf{a}}$.

\begin{tabular}{ccccccc}
\hline $\begin{array}{c}\text { Age } \\
\text { Group }\end{array}$ & $\begin{array}{c}\text { Body Weight } \\
(\mathbf{k g})\end{array}$ & S.D. & $\begin{array}{c}\text { Dust ingestion } \\
(\mathbf{m g} / \mathbf{d a y})\end{array}$ & $\begin{array}{c}\text { S.D. } \\
\text { Body Surface Area to } \\
\text { Body Weight Ratio } \\
\left(\mathbf{m}^{2} / \mathbf{k g}\right)\end{array}$ & S.D. \\
\hline Adults & 80 & 20.73 & 30 & 4.2 & 0.028 & 0.003
\end{tabular}

229 a Dust ingestion rate and body weights are mean values recommended in the U.S. EPA's Exposure Factors 230 Handbook.

231

232

233 
234 Table S3. General model characteris tics ${ }^{[32]}$.

\begin{tabular}{ccc}
\hline Characteristic (units) & Term & Mean Value (CV) \\
\hline Fraction of total body surface area exposed (unitless) & AE & $0.3(0.3)$ \\
Dust adherence rate $\left(\mathrm{g} / \mathrm{m}^{2}\right)$ & A & $0.04(0.3)$ \\
\hline
\end{tabular}

235

236 
237 Table S4. Chemical abbreviation used in this study.

\begin{tabular}{lc}
\hline \multicolumn{1}{c}{ Chemical name } & Abbreviation \\
\hline benzo(a)anthracene & $\mathrm{BA}$ \\
benzo(a)pyrene & $\mathrm{B}(\mathrm{a}) \mathrm{P}$ \\
benzo(b,k)fluoranthene & $\mathrm{B}(\mathrm{bk}) \mathrm{F}$ \\
benzo(k)fluoranthene & $\mathrm{BkF}$ \\
bis (2-ethylhexyl) phthalate & $\mathrm{DEHP}$ \\
bisphenol A diglycidyl ether & $\mathrm{BADGE}$ \\
dibenzo(a,h)anthracene & $\mathrm{DB}(\mathrm{a}, \mathrm{h}) \mathrm{A}$ \\
dibutyltin dichloride & $\mathrm{DBTC}$ \\
diisononyl phthalate & $\mathrm{DINP}$ \\
hexabromobenzene & $\mathrm{HBB}$ \\
methyl palmitate & $\mathrm{MP}$ \\
myristic acid & $\mathrm{MA}$ \\
oleic acid & $\mathrm{OA}$ \\
palmitic acid & $\mathrm{PA}$ \\
perfluorohexanoic acid & PFHxA \\
triclocarban & TCC \\
tri (2-butoxyethyl) phosphate & TBOEP \\
tri-o-cresyl phosphate & TOCP \\
\hline
\end{tabular}




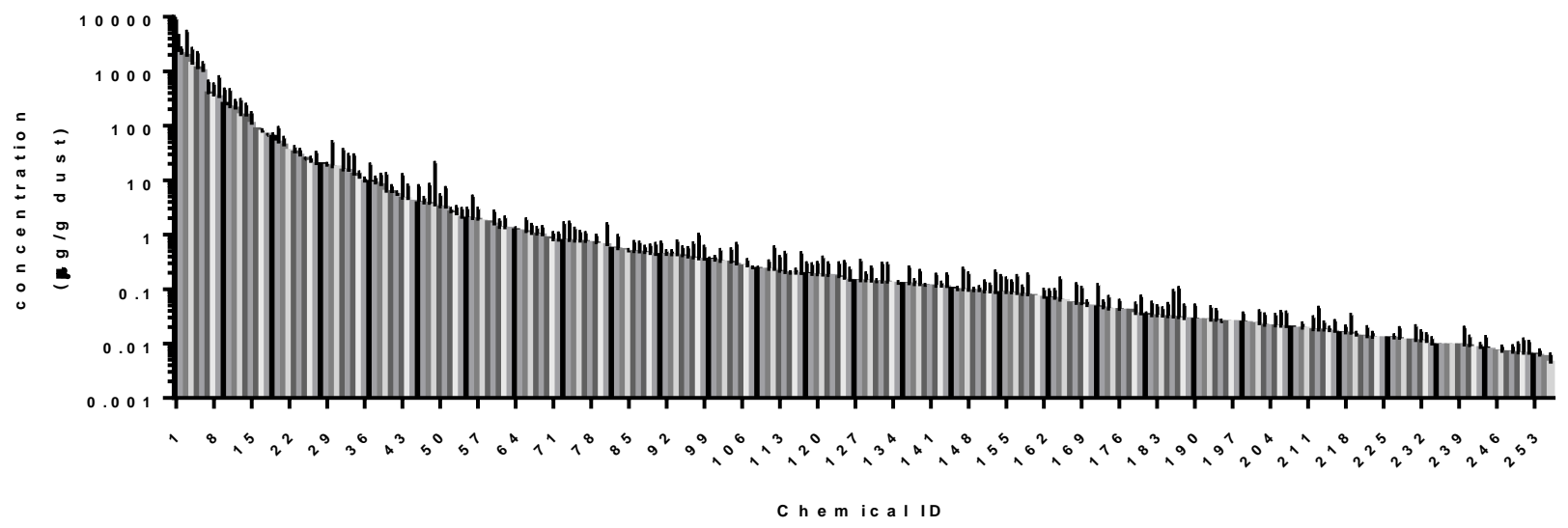

244 Figure S1. The variation of ave raged median concentrations of indoor dust chemicals 245 across studies $(\mathbf{n} \geqslant 4)$. Each bar represents the average of a chemical's mean concentrations 246 from different studies and error bars represent the sample size weighted standard deviation. The 247 chemical ID can be found in Table S1. 


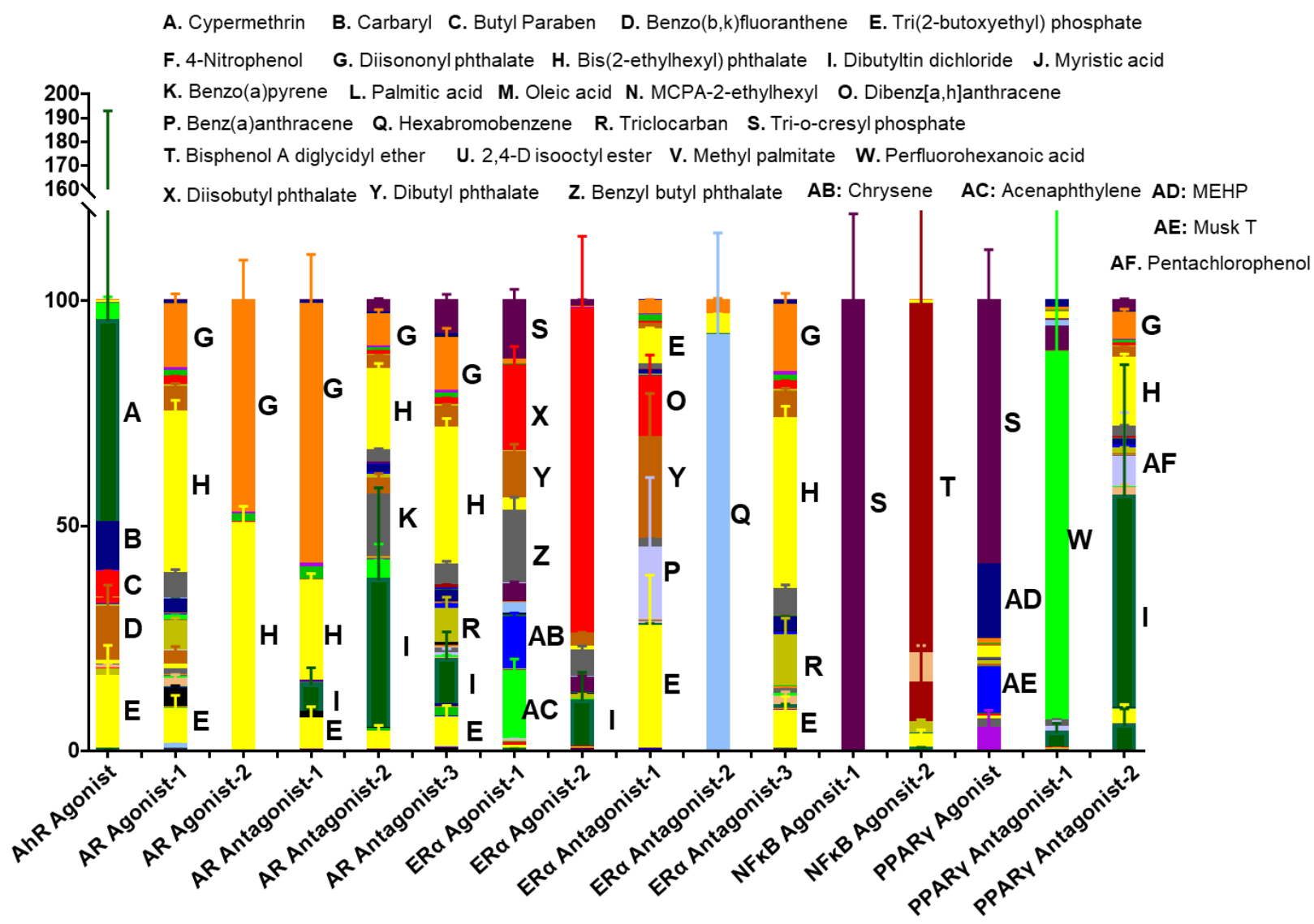

252 Figure S2. Chemical contributions in every assay. In each assay, the important chemicals

253 without concentration standard deviation or study number $<2$ were removed (study number $\geq 2$ ). 
A

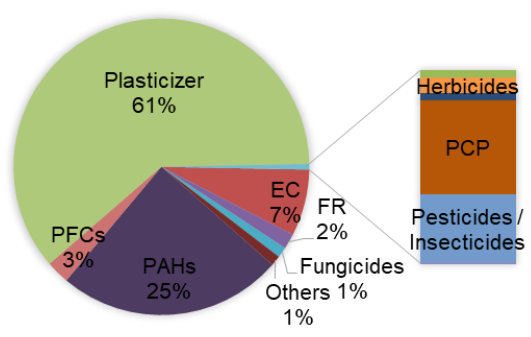

ERa Agonist-1
B

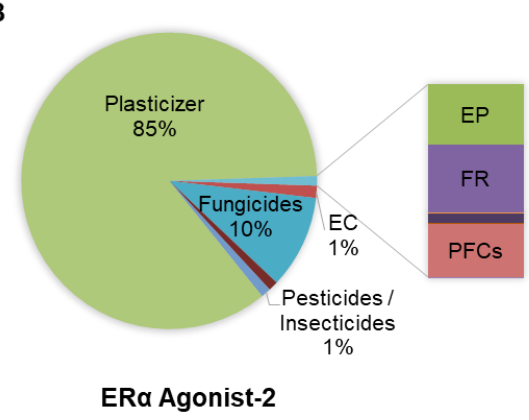

258 Figure S3. Toxicity contribution from che micals in dust in two ERa agonist assays. The top 259 one chemical in two assays were MCPA-2-ethylhexyl and palmitic acid, respectively, which 260 were retrieved from one study, and without considering these two important chemicals, the 261 results were shown in $\mathrm{A}$ and $\mathrm{B}$. 


\section{References}

265 1. Peng, H.; Saunders, D. M.; Sun, J.; Jones, P. D.; Wong, C. K.; Liu, H.; Giesy, J. P., Mutagenic

266

267

268

269

270

271

272

273

274

275

276

277

278

279

280

281

282

283

284

285

286

287

288

289

290

291

292

293

294

295

296

azo dyes, rather than flame retardants, are the predominant brominated compounds in house dust. Environmental science \& technology 2016, 50, (23), 12669-12677.

2. Rager, J. E.; Strynar, M. J.; Liang, S.; McMahen, R. L.; Richard, A. M.; Grulke, C. M.; Wambaugh, J. F.; Isaacs, K. K.; Judson, R.; Williams, A. J., Linking high resolution mass spectrometry data with exposure and toxicity forecasts to advance high-throughput environmental monitoring. Environment international 2016, 88, 269-280.

3. ATSDR, Public Health Assessment Guidance Manual. In Control, C. f. D., Ed. Atlanta, GA, 2005.

4. Suzuki, G.; Someya, M.; Takahashi, S.; Tanabe, S.; Sakai, S.; Takigami, H., Dioxin-like activity in Japanese indoor dusts evaluated by means of in vitro bioassay and instrumental analysis: brominated dibenzofurans are an important contributor. Environmental science \& technology 2010, 44, (21), 8330-6. 5. Chou, P. H.; Lee, C. H.; Ko, F. C.; Lin, Y. J.; Kawanishi, M.; Yagi, T.; Li, I. C., Detection of Hormone-Like and Genotoxic Activities in Indoor Dust from Taiwan Using a Battery of in Vitro Bioassays. Aerosol Air Qual Res 2015, 15, (4), 1412-+.

6. Suzuki, G.; Takigami, H.; Nose, K.; Takahashi, S.; Asari, M.; Sakai, S., Dioxin-like and transthyretin-binding compounds in indoor dusts collected from Japan: average daily dose and possible implications for children. Environmental science \& technology 2007, 41, (4), 1487-93.

7. Tue, N. M.; Suzuki, G.; Takahashi, S.; Kannan, K.; Takigami, H.; Tanabe, S., Dioxin-related compounds in house dust from New York State: occurrence, in vitro toxic evaluation and implications for indoor exposure. Environ Pollut 2013, 181, 75-80.

8. $\quad$ Tuyen, L. H.; Tue, N. M.; Takahashi, S.; Suzuki, G.; Viet, P. H.; Subramanian, A.; Bulbule, K. A.; Parthasarathy, P.; Ramanathan, A.; Tanabe, S., Methylated and unsubstituted polycyclic aromatic hydrocarbons in street dust from Vietnam and India: occurrence, distribution and in vitro toxicity evaluation. Environ Pollut 2014, 194, 272-280.

9. $\quad$ Suzuki, G.; Tue, N. M.; Malarvannan, G.; Sudaryanto, A.; Takahashi, S.; Tanabe, S.; Sakai, S.; Brouwer, A.; Uramaru, N.; Kitamura, S.; Takigami, H., Similarities in the endocr ine-disrupting potencies of indoor dust and flame retardants by using human osteosarcoma (U2OS) cell-based reporter gene assays. Environmental science \& technology 2013, 47, (6), 2898-908.

10. Kennedy, K.; Macova, M.; Leusch, F.; Bartkow, M. E.; Hawker, D. W.; Zhao, B.; Denison, M. S.; Mueller, J. F., Assessing indoor air exposures using passive sampling with bioanalytical methods for estrogenicity and aryl hydrocarbon receptor activity. Analytical and bioanalytical chemistry 2009, 394, (5), 1413-21. 
11. Feige, J. N.; Gelman, L.; Rossi, D.; Zote, V.; Metivier, R.; Tudor, C.; Anghel, S. I.; Grosdidier, A.; Lathion, C.; Engelborghs, Y.; Michielin, O.; Wahli, W.; Desvergne, B., The endocrine disruptor monoethyl-hexyl-phthalate is a selective peroxisome proliferator-activated receptor gamma modulator that promotes adipogenesis. J Biol Chem 2007, 282, (26), 19152-19166.

12. Grun, F.; Watanabe, H.; Zamanian, Z.; Maeda, L.; Arima, K.; Chubacha, R.; Gardiner, D. M.; Kanno, J.; Iguchi, T.; Blumberg, B., Endocrine-disrupting organotin compounds are potent inducers of adipogenesis in vertebrates. Mol Endocrinol 2006, 20, (9), 2141-2155.

13. Fang, M.; Webster, T. F.; Ferguson, P. L.; Stapleton, H. M., Characterizing the peroxisome proliferator-activated receptor (PPARgamma) ligand binding potential of several major flame retardants, their metabolites, and chemical mixtures in house dust. Environ Health Persp 2015, 123, (2), 166-72.

14. Fang, M.; Webster, T. F.; Stapleton, H. M., Activation of Human Peroxisome ProliferatorActivated Nuclear Receptors (PPARgamma1) by Semi-Volatile Compounds (SVOCs) and Chemical Mixtures in Indoor Dust. Environ Sci Technol 2015, 49, (16), 10057-64.

15. Fang, M.; Webster, T. F.; Stapleton, H. M., Effect-Directed Analysis of Human Peroxisome Proliferator-Activated Nuclear Receptors (PPARgamma1) Ligands in Indoor Dust. Environ Sci Technol 2015, 49, (16), 10065-73.

16. Grun, N. G.; Zeyda, K.; Moreno-Viedma, V.; Strohmeier, K.; Staffler, G.; Zeyda, M.; Stulnig, T. M., A humanized osteopontin mouse model and its application in immunometabolic obesity studies. Translational research : the journal of laboratory and clinical medicine 2016, 178, 63-73 e2.

17. Pillai, H. K.; Fang, M.; Beglov, D.; Kozakov, D.; Vajda, S.; Stapleton, H. M.; Webster, T. F.; Schlezinger, J. J., Ligand binding and activation of PPARgamma by Firemaster(R) 550: effects on adipogenesis and osteogenesis in vitro. Environmental health perspectives 2014, 122, (11), 1225-32.

18. Kassotis, C. D.; Hoffman, K.; Stapleton, H. M., Characterization of Adipogenic Activity of House Dust Extracts and Semi-Volatile Indoor Contaminants in 3T3-L1 Cells. Environmental science \& technology 2017, 51,(15), 8735-8745.

19. Hu, P.; Chen, X.; Whitener, R. J.; Boder, E. T.; Jones, J. O.; Porollo, A.; Chen, J.; Zhao, L., Effects of parabens on adipocyte differentiation. Toxicological sciences : an official journal of the Society of Toxicology 2013, 131,(1), 56-70.

20. Maertens, R. M.; Gagne, R. W.; Douglas, G. R.; Zhu, J. P.; White, P. A., Mutagenic and carcinogenic hazards of settled house dust II: Salmonella Mutagenicity. Environmental science \& technology 2008, 42, (5), 1754-1760.

21. Maertens, R. M.; Yang, X. F.; Zhu, J. P.; Gagne, R. W.; Douglas, G. R.; White, P. A., Mutagenic and carcinogenic hazards of settled house dust I: Polycyclic aromatic hydrocarbon content and excess 
lifetime cancer risk from preschool exposure. Environmental science \& technology 2008, 42, (5), 17471753.

22. Peng, H.; Saunders, D. M. V.; Sun, J. X.; Jones, P. D.; Wong, C. K. C.; Liu, H. L.; Giesy, J. P., Mutagenic Azo Dyes, Rather Than Flame Retardants, Are the Predominant Brominated Compounds in House Dust. Environmental science \& technology 2016, 50, (23), 12669-12677.

23. Stein, M. M.; Hrusch, C. L.; Gozdz, J.; Igartua, C.; Pivniouk, V.; Murray, S. E.; Ledford, J. G.; Marques Dos Santos, M.; Anderson, R. L.; Metwali, N.; Neilson, J. W.; Maier, R. M.; Gilbert, J. A.; Holbre ich, M.; Thorne, P. S.; Martinez, F. D.; von Mutius, E.; Vercelli, D.; Ober, C.; Sperling, A. I., Innate Immunity and Asthma Risk in Amish and Hutterite Farm Children. The New England journal of medicine 2016, 375, (5), 411-421.

24. Schuijs, M. J.; Willart, M. A.; Vergote, K.; Gras, D.; Deswarte, K.; Ege, M. J.; Madeira, F. B.; Beyaert, R.; van Loo, G.; Bracher, F.; von Mutius, E.; Chanez, P.; Lambrecht, B. N.; Hammad, H., Farm dust and endotoxin protect against allergy through A20 induction in lung epithelial cells. Science 2015, 349, (6252), 1106-10.

25. Hammad, H.; Chieppa, M.; Perros, F.; Willart, M. A.; Germain, R. N.; Lambrecht, B. N., House dust mite allergen induces asthma via Toll-like receptor 4 triggering of airway structural cells. Nature medicine 2009, 15, (4), 410-6.

26. Tully, J. E.; Hoffman, S. M.; Lahue, K. G.; Nolin, J. D.; Anathy, V.; Lundblad, L. K. A.; Daphtary, N.; Aliyeva, M.; Black, K. E.; Dixon, A. E.; Poynter, M. E.; Irvin, C. G.; Janssen-Heininger, Y. M. W., Epithelial NF-kappa B Orchestrates House Dust Mite-Induced Airway Inflammation, Hyperresponsiveness, and Fibrotic Remodeling. J Immunol 2013, 191,(12), 5811-5821.

27. Tully, J. E.; Nolin, J. D.; Guala, A. S.; Hoffman, S. M.; Roberson, E. C.; Lahue, K. G.; van der Velden, J.; Anathy, V.; Blackwell, T. S.; Janssen-Heininger, Y. M. W., Cooperation between Classical and Alternative NF-kappa B Pathways Regulates Proinflammatory Responses in Epithelial Cells. Am J Resp Cell Mol 2012, 47, (4), 497-508.

28. Ather, J. L.; Hodgkins, S. R.; Janssen-Heininger, Y. M. W.; Poynter, M. E., Airway Epithelial NF-kappa B Activation Promotes Allergic Sensitization to an Innocuous Inhaled Antigen. Am J Resp Cell Mol 2011, 44, (5), 631-638.

29. Meeker, J. D.; Stapleton, H. M., House Dust Concentrations of Organophosphate Flame Retardants in Relation to Hormone Levels and Semen Quality Parameters. Environmental health perspectives 2010, 118, (3), 318-323.

30. Hoffman, K.; Lorenzo, A.; Butt, C. M.; Hammel, S. C.; Henderson, B. B.; Roman, S. A.; Scheri, R. P.; Stapleton, H. M.; Sosa, J. A., Exposure to flame retardant chemicals and occurrence and severity of papillary thyroid cancer: A case-control study. Environment international 2017, 107, 235-242. 
364 31. SCAQMD, Multi-Pathway Health Risk Assessment Input parameters Guidance Document In 365 District, T. C. S. C. A. Q. M., Ed. 1988.

366 32. EPA, U. S., Exposure Factors Handbook 2011 Edition (Final). In Agency, U. S. E. P., Ed. 367 Washington, DC. , 2011.

368

369 